\title{
Determinants of Substance Abuse among Commercial Bus Drivers in Kano Metropolis, Kano State, Nigeria
}

\author{
Umar Yunusa ${ }^{1}$, Umar Lawal Bello ${ }^{1, ~ *, ~ M u n i r ~ I d r i s ~}{ }^{2}$, Mahfuz Muhammad Haddad ${ }^{1}$, \\ Dalhatu Adamu ${ }^{1}$ \\ ${ }^{1}$ Department of Nursing Sciences, Faculty of Allied Health Sciences, Bayero University Kano, Kano State, Nigeria \\ ${ }^{2}$ Department of Nursing Services, Murtala Muhammad Specialist Hospital Kano, Kano State, Nigeria
}

Email address:

ulbello.nur@buk.edu.ng (U. L. Bello)

${ }^{*}$ Corresponding author

\section{To cite this article:}

Umar Yunusa, Umar Lawal Bello, Munir Idris, Mahfuz Muhammad Haddad, Dalhatu Adamu. Determinants of Substance Abuse among Commercial Bus Drivers in Kano Metropolis, Kano State, Nigeria. American Journal of Nursing Science. Vol. 6, No. 2, 2017 , pp. 125-130. doi: 10.11648/j.ajns.20170602.16

Received: December 20, 2016; Accepted: December 29, 2016; Published: February 24, 2017

\begin{abstract}
Background: The use of illicit substances among commercial bus drivers is not only increasing but strangely predisposing the drivers and their passengers to health hazards. There is however paucity of empirical data on the factors associated with this increase. Aim: This study was conducted to explore the determinants of substance abuse among commercial bus drivers in Kano Metropolis, Kano state, Nigeria. Methodology: A descriptive cross sectional design was used for the study where by 196 respondents were selected through a multi-stage cluster sampling technique. A validated and structured interviewer administered questionnaire (IAQ) was used to collect data from the eligible respondents. The data were analysed using descriptive statistics. Results: Findings from the study showed that eight out of every ten (81.1\%) of the respondents has ever abused a substance. The desires to relax/sleep after a hard days job (84.8\%), work hard (48\%), relieve stress $(81 \%)$, relieve anxiety $(66.5 \%)$ and pleasure $(72 \%)$ are the major factors associated with the abuse of substances by the respondents. The most commonly abused substances by the respondents include solution (93.3\%) coffee (85.2\%), Tramadol (80.6\%), local stimulant tea (Gadagi) (78.1\%), cola-nut (66.3\%) and tobacco (65\%), Substance abuse can be reduced by controlling the production and sale of commonly abused substance (27.6\%). Conclusion: The major determinants of substance abuse among commercial bus drivers are the desires to work hard, relieve of stress and anxiety. It is therefore recommended that Government should control the production, supply and sale of these illicit substances.
\end{abstract}

Keywords: Determinants, Substance, Abuse, Bus Drivers, Commercial

\section{Introduction}

Substance abuse, also known as drug abuse, is a patterned use of a drug in which the user consumes the substance in amounts or with methods which are harmful to themselves or others (Nutt, King, Saulsbury \& Blakemore, 2010). The use of illicit drugs across the globe has increased in recent years (Ekpenyong, 2012). It is estimated that about 230 million people $(5 \%)$ out of the world's adult population have used an illicit drug at least once in the last 12 months of the survey (United Nations Office on Drugs and Crime UNODC, 2012). Given the dearth of scientific survey in Africa, information on drug use in the region is extremely inadequate. However theannual prevalence rate in Africa for cannabis use fluctuates roughly between 4 and 14 per cent, and is the highest in the world. Nigeria tops in the use of illicit drugs in Africa (UNODC, 2012).

The number of youths that have been incarcerated and indulged in various forms of crime in Nigeria have increased over the last few decades (National Drug Law Enforcement Agency, NDLEA, 2014). It has been estimated that Heroin, cocaine and other drugs kill around 0.2 million people each year, shattering families and bringing misery to thousands of other people. Illicit drugs undermine economic and social development and contribute to crime, instability, insecurity and the spread of HIV (NDLEA, 2014). The specific illicit 
drugs with the largest numbers of persons with past year dependence or abuse in 2013 were marijuana (4.2 million), pain relievers (1.9 million), and cocaine $(855,000)$. (National Survey on Drug Use and Health NSDUH, 2013).

The major influences of smoking among youths are friends (Winters, 2009). In addition, advertisements, film, TV stars, pop stars and fashion models make smoking seem attractive and the adolescents imitate them to smoke their style (Jiloha, 2011: Nutt et al, 2010). Parents have a tremendous influence on their children as the children of smoker parents are twice likely to become smokers. Parental disapproval of smoking makes an adolescent less likely to initiate smoking (Winters, 2009). Cannabis abuse in school-going population has been associated with poor scholastic performance, school dropout and reinforcement of conduct symptoms (Rockville, 2005). Availability and accessibility are important factors in initiation and maintenance of drug abuse among adolescents. (Nutt et al, 2010).

Drug abuse in northern Nigeria's largest city (Kano) has been on the rise in recent years, with anti-narcotics officials and experts warning of serious social consequences if the problem is not addressed. Kano has the country's highest drug abuse rate based on the number of seizures, arrests of addicts and convictions of arrested dealers, according to the National Drug Law Enforcement Agency (NDLEA, 2013). The use of hard drugs, especially among the youths, has become a real social menace and cuts across all social strata, with people from both rich and poor backgrounds deeply into it (NDLEA, 2013).

The use of illicit substance cuts across every sector, occupation, gender and area. With the increase in the rate of road traffic accidents and injuries in the state, commercial bus drivers have also been implicated in the use of illicit substances. According to the World Health Organization (2007) studies from low-middle income countries still show $4 \%-69 \%$ of injured drivers having alcohol in their blood. A significant proportion of commercial drivers use stimulants to keep awake and relieve fatigue during their long work schedules. (Davey \& Richards, 2005). Intoxicants such as alcohol and marijuana affect the mental state of drivers leading to altered perceptions and delayed reactions, increasing the risk for having Road Traffic Accident (Drummer, 2005). The high incidence of road traffic accident observed now in our society is thought to be directly linked with high incidence of substance use among commercial bus drivers, likewise other immoral behaviours among them which is a serious problem to the peaceful coexistence of people they interact with especially their passengers. Aggressive behaviours are common and routine in their day to day life. (Taiwo, 2015)

Since the National Drug Law Enforcement Agency (NDLEA) was set-up in 1999, frantic efforts are being made to collect relevant information on drugs through variety of drug indicators for policy formulation. The impact of this agency in terms of intervention strategies and control is tremendous. (Essien, 2010). There is however a dearth of empirical evidence on why substance abuse is not only common among commercial bus drivers but persisting and increasing. Hence this study was conducted to explore the determinants of substance abuse among commercial bus drivers in Kano Metropolis. Findings from the study will help in creating awareness in the society on the general effects of substance abuse on their health and to provide policy makers with empirical data on the strategies to control the menaceof substance abuse.

\section{Methodology}

\subsection{Research Design and Instrument}

A cross sectional survey design was used for the study. Data was collected with a validated interviewer administered questionnaire (IAQ). The questionnaire comprised 5 sections: section A, covers the bio-data of the respondent; section $\mathrm{B}$, the rate of substance abuse and section $C$ covers the factors associated with substance use. Sections D and E elicited the commonly abused substances and measures that can be used to reduce substance abuse respectively. The target population of the study encompasses all the commercial bus drivers in Kano metropolis.

\subsection{Study Setting}

This study was conducted in Kano Metropolis, Kano State in Northern Nigeria. The state is the commercial center of Northern Nigeria and is the second largest city in Nigeria after Lagos. According to the 2006 census, Kano is the most populous state in Nigeria, with about 9,383,682 million people. The Kano urban area covers $137 \mathrm{~km}^{2}$ and comprises six local government areas (LGAs) Kano Municipal, Fagge, Dala, Gwale, Tarauni and Nassarawa with a population of 2,163,225 at the 2006 Nigerian census. The metropolitan area covers $499 \mathrm{~km}^{2}$ and comprises eight LGAs the six mentioned above plus Ungogoand Kumbotso with a population of 2,828,861 at the 2006 Nigerian census (Benyard, 2005). Kano metropolis was chosen as the study area as a result of high prevalence of substance abuse as reported recently by agencies concerned with fighting substance abuse.

\subsection{Sample Size and Sampling Technique}

A sample size of 196 was obtained by utilizing the Kirkwood formula for determining sample sizen $=z^{2} p(1-$ $\mathrm{p}) / \mathrm{e}^{2}$ (Kirkwood, 2003). Where $\mathrm{n}=$ the acquired minimum sample size, $e=$ margin of error $(5 \%)=0.05, p=$ prevalence $(a$ prevalence indicator of $85 \%$ by Moses (2010) was used for the this study, $\mathrm{z}=$ standard normal deviation corresponding to $95 \%$ confidence level. $=1.96$. the sample size was increased by $5 \%$ to 206 to control attrition.

A multistage cluster sampling technique was used to select six out of the eight local governments in Kano metropolis using simple random sampling technique, the selected local government areas are Nassarawa, Gwale, Municipal, Kumbotso, Tarauni and Ungoggo local Governments respectively. Two political wards were then selected from each of the six local governments using 
judgmental non probability sampling. A single motor park was then selected from each of the selected wards using convenience non probability sampling. A total of 16 commercial bus drivers were selected from eight (8) of the 12 selected motor parks, and 17 respondents were selected from the remaining four motor parks using convenience sampling technique.

\subsection{Ethical Clearance and Data Collection}

Ethical clearance for the study was sought from Kano State Ministry of Health with reference number MOH/Off/797/T.I/53. Eligible respondents were voluntarily recruited at the selected bus parks. They were informed of the purpose of the study, their roles, possible benefits and risks of participating in the study and then allowed to make an informed consent to participate in the study. The researcher read the questions and options from the questionnaire and asked the respondent to choose the appropriate answer. Data collected was treated with confidentiality.

\subsection{Data Analysis}

The data was entered in the statistical package of social sciences (SPSS version 20) and the result was presented in simple frequency distribution tables and percentages. The mean of the ages of respondents was computed.

\section{Results}

Results as indicated in Table 1 revealed that all $(100 \%)$ of the respondents are male. More than two fifth $(45.4 \%)$ of the respondents are within the age range of 25-34 years. The respondents have an average age of 32.3 years. Findings of the study further showed that more than one third $(36.7 \%)$ of the respondents had primary education as their highest qualification. The proportion of respondents that earn between $\$ 21,000 / \$ 42$ and $\$ 30,000 / \$ 63(42.9 \%$ ) was nearly twice that of those that earn from $\$ 31,000 / \$ 64$ to $40,000 / \$ 83(23 \%)$.

Table 2 revealed that more than eight out of every ten $(81.1 \%)$ of the respondents takes one form of substance or the other. The proportion of respondents that abused more than one substance at a time $(49.4 \%)$ was similar to those that abused only one substance $(50.6 \%)$. More than half $(53.6 \%)$ of the respondents abused substances about 2-3 times in a day. The Table also indicated that the reasons why commercial bus drivers abused substances are to relax/sleep after a hard days job (84.8\%), work hard (48\%), relieve stress $(81 \%)$, relieve anxiety $(66.5 \%)$ and pleasure $(72 \%)$.

Table 1. Distribution of the respondents by bio-demographic data $N=196$.

\begin{tabular}{lll}
\hline Variables & Frequency & Percentage (\%) \\
\hline Sex & & \\
Male & 196 & 100 \\
Female & 0 & 0 \\
Age in years & & \\
\hline
\end{tabular}

\begin{tabular}{lll}
\hline Variables & Frequency & Percentage (\%) \\
\hline $15-24$ & 32 & 16.3 \\
$25-34$ & 89 & 45.4 \\
$35-44$ & 64 & 32.7 \\
$45-54$ & 11 & 5.6 \\
Mean Age: 32.3 years & & \\
Level of education & & \\
No formal education & 34 & 17.3 \\
Quranic education & 46 & 23.5 \\
Primary education & 72 & 36.7 \\
Secondary education & 44 & 22.4 \\
Tertiary education & 0 & 0 \\
Average monthly Income in Naira (\$) & \\
Below 20,000 (<42) & 34 & 17.3 \\
21000 (42)-30,000 (63) & 84 & 42.9 \\
31000 (64)-40,000 (83) & 45 & 23.0 \\
$41000(85)-50,000(104)$ & 27 & 13.8 \\
$51000(106)-60000(125)$ & 5 & 2.6 \\
61000 (127) -70,000 (145) & 1 & 0.5 \\
Above 70,000 (>145) & 0 & 0 \\
\hline
\end{tabular}

Table 2. Distribution of the respondents by rate of abused substance.

\begin{tabular}{|c|c|c|}
\hline Variables & Frequency & Percentage $(\%)$ \\
\hline \multicolumn{3}{|c|}{ Use of substance other than those required for medical reasons $\mathrm{N}=196$} \\
\hline Yes & 158 & 81.1 \\
\hline No & 38 & 18.9 \\
\hline \multicolumn{3}{|c|}{ Abuse of more than one substance at a time $\mathrm{N}=158$} \\
\hline Yes & 78 & 49.4 \\
\hline No & 80 & 50.6 \\
\hline \multicolumn{3}{|c|}{ Frequency of substance intake $\mathrm{N}=151$} \\
\hline 1-2 times. & 56 & 37.1 \\
\hline 2-3 times. & 81 & 53.6 \\
\hline$>3$ times. & 14 & 9.3 \\
\hline \multicolumn{3}{|c|}{ Ability to stop using substance $\mathrm{N}=156$} \\
\hline Yes & 31 & 19.9 \\
\hline No & 125 & 80.1 \\
\hline \multicolumn{3}{|c|}{ Reasons of substance use other than those required for medical reasons. } \\
\hline To work hard & 52 & 48 \\
\hline To relieve anxiety & 33.5 & 66.5 \\
\hline To relieve stress & 19 & 81 \\
\hline To relax/sleep & 15.2 & 84.8 \\
\hline For pleasure & 28 & 72 \\
\hline
\end{tabular}

Table 3 revealed that commonly abused substances by the commercial bus drivers are solution (93.3\%), coffee $(85.2 \%)$, tramadol $(80.6 \%)$, local stimulant tea (Gadagi) $(78.1 \%)$, colanut $(66.3 \%)$ and tobacco $(65 \%)$. The Table further showed that more than one quarter $(28.5 \%)$ of the respondents have used some measures to control themselves from taking substance. Measures that have been tried by the respondents to stop or control substance abuse include avoiding the substance $(76.4 \%)$, suppressing the desire to take the substances $(82.9 \%)$ and prayers seeking God's intervention (29.9\%). Strategies that can be used to stop or control substance abuse as suggested by the respondents include health education $(81.1 \%)$, controlling the production, distribution and availability of the substances (72.4\%), rehabilitation of commercial bus drivers engaged in substance abuse (91.8\%) and spiritual intervention (91.8\%). 
Table 3. Percentage distributions of the respondents on commonly abused substance. $N=196$.

\begin{tabular}{lcc}
\hline Commonly abused substance & Yes (\%) & No (\%) \\
\hline Substance(s) that are commonly abused. & & \\
Tobacco & 35 & 65 \\
Cola nut & 33.7 & 66.3 \\
Tramadol & 19.4 & 80.6 \\
Coffee & 14.8 & 85.2 \\
Gadagi & 21.9 & 78.1 \\
Marijuana & 23.5 & 76.5 \\
Solutions & 6.7 & 93.3 \\
Proportion of respondents that have tried to stop or control substances \\
abuse. N=158 & & \\
Tried & 45 & 28.5 \\
Never tried & 113 & 71.5 \\
Measures previously used by respondents to stop or control substance \\
abuse N=144 & \\
Avoidance of substance & 110 & 76.4 \\
Suppressing the desire & 131 & 82.9 \\
Prayers for God's intervention & 43 & 29.9 \\
Strategies that can be used to stop/control substance abuse among \\
commercial bus drivers N=196 & \\
Health education & 159 & 81.1 \\
Control of abused substance & 142 & 72.4 \\
Rehabilitation & 180 & 91.8 \\
Spiritual support & 180 & 91.8 \\
\hline
\end{tabular}

\section{Discussion}

Findings of the study revealed that majority of the commercial bus drivers in Kano metropolis were young adults with educational qualification below secondary school level. This is connected with the reality of the stress and competition associated with the occupation. This validates the findings of study conducted by Alti, Muazu \& Aliyu (2008) in Zaria where majority (55.5\%) of the drivers were in the age group 21-25 years. There is therefore the need to target education on the effects of substance abuse to the youths. It is also important to provide an enabling environment that will facilitate the youths to obtain formal education and to be gainfully employed in less vulnerable occupations. The low monthly income of the commercial bus drivers is likely associated with the availability of other alternative means of transportation in the metropolis.

The result of the study revealed that an overwhelming majority of the respondents engage in one form of substance abuse or the other. Findings based on the type of substances abused showed that the commercial bus drivers abuse substances that are cheap and readily available to them such as tramadol, coffee, Kola nut and local tea. This corroborates findings of study conducted in Zaria where marijuana [Indian hemp] $25.8 \%$, solution $24.5 \%$, caffeine (Kola) $15.8 \%$, and coffee $4.8 \%$ are the major substances abused by commercial motorcyclists. (Alti, Muazu \& Aliyu, 2008). This is not unrelated to the reason why about two fifth of the respondents abuse more than one substance at a time. There is therefore the need for the government to enact laws to control the production and availability of such substances.

The study revealed that the desires to work hard and make more income and to relieve stress after a long day work are the major reasons why the respondents engage in substance abuse. This validates findings of Alti, Muazu \& Aliyu (2008) where keeping awake, suppression of fatigue, and peer group effect were the identified factors influencing psychoactive substance use.

Some of the respondents have used measures to control themselves from taking substance. This is true because it has been established that only few individuals have the ability or measures that can be used to control themselves from taking substance. Likewise more than two fifth of the respondents control themselves from taking substance by avoiding them and the remaining respondents did not mention avoidance as a measure of prevention or control of substance abuse. It has been established in this research work that More than three fifth of the respondents control themselves from substance intake by suppressing the desire to take the substance. Also more than one fifth of the respondents say their prayers seeking God's intervention in prevention and control of substance use, people have the belief that with God everything is possible.

Strategies that can be used to stop or control substance abuse as suggested by the respondents include health education, controlling the production, distribution and availability of the substances, rehabilitation of commercial bus drivers engaged in substance abuse, and spiritual intervention. The study showed that there is a significant relationship between the age of respondents and the rate of substance abuse which explains why a significant majority of the respondents that abuse substance are young adults.

\section{Conclusion and Recommendation}

The study concluded that the major determinants of substance abuse include the desire to work hard, desire to relieve stress, anxiety relief, desire to relax, pleasure seeking stimulus and most importantly age (young adults). It is therefore recommended that Government control the production, supply and sale of commonly abused substances. Nurses and other health care workers educate youths on the importance of rest to the body. The commercial bus drivers and the general public should be enlightened on the dangers and the health implication of substance abuse. The National Drug Law Enforcement Agency should work with National Agency for Food Drug Administration and Control, National Union of Road Transport Workers and health care workers to prevent this illicit act.

\section{References}

[1] Alti, Muazu M., Aliyu, A. A. (2008) Prevalence of psychoactive substance use among commercial motorcyclists and its health and social consequences in Zaria, Nigeria. Ann Afr Med, 7(2):67-71.

[2] American psychiatric association diagnostic and statistical manual of mental disorder $4^{\text {th }}$ ed. Washington DC American psychiatric association. 
[3] Banyard, p. (2005) psychology in practice and health 0-34084496-5.

[4] Bales, R. F. (2010) cultural differences in the rate of alcoholism. Quarterly journal of studies on alcohol. Newyork: oxford university press.

[5] Bako, M. (2015) interview on the determinants of substance abuse among commercial bus drivers.

[6] Blum, B. \& Moore, A. (2006), controlling drugs. An international handbook for psychoactive drug classification. New York: oxford university press.

[7] Ballas, P. (2009) news and features, department of psychiatry, Thomas Jefferson University Hospital, Philadelphia.

[8] Bruce, E. (2010) centre for substance abuse treatment screening and assessing adolescents forSubstance use disorders. Treatment improvement protocol (TIP) series, No.31.DHHS publication No. (SMA) 99-3282.

[9] Chisholm M. \& Naci A. (2008) how do dopamine and neurons represent positive and negative Motivational events? National institute of health, 459,837-841.

[10] Centre for Disease Control and prevention Newsroom (CDC) Press Release June 3, 2010.

[11] Dele, A. (july 11 2015): drug abuse, the Nations newspaper. Page 25.

[12] Darryl S and William, (2009)"Uppers, Downers, AllArounders: Physical and Mental Effects of. Psychoactive Drugs"; kamar New York.

[13] Drummer, D., (2010). Drug use and addiction: evolutionary perspective. Australian and New Zealand Journal of Psychiatry, 43(11) 1049-1056.

[14] Drobes, D. J. (2005). Concurrent Alcohol and Tobacco Dependence. National Institute of Alcohol

[15] Abuse and Alcoholism. Retrieved on 20 sept., 2015 from: http://pubs.niaaa.nih.gov/publications/arh26-2/136-142.htm

[16] Durant D. (2009). Psychotherapy for the Treatment of Substance Abuse. American Psychiatric Publishing, Washington D.C.

[17] Davey S. M. \& Richard k. (2005). Relapse and Recovery: Behavioral Strategies for Change. Excellence in Addiction Treatment. Pg. 1-24.

[18] Darryl E. \& William F. (2010) mental and physical effect of psychoactive drugs.

[19] Department of Education's Safe and Drug-Free Schools and Communities Program (SDFSP), 2010

[20] Ekpenyong, S. N. (2012). Drug Abuse in Nigerian Schools: A Study of Selected Secondary Institutions in Bayelsa State, South-South, Nigeria. International Journal of Scientific Research in Education, 5(3), 260-268. Retrieved [25/07/2015] http://www.ijsre.com.

[21] Essien, F. (2010) drug use and abuse among students in tertiary institutions. [electronic version], journal of research in national development, 8(2), 23-26.

[22] Everitt, B. J. \& Robbins T. W. (2005). Neural Systems of Reinforcement for Drug Addiction: From Actions to Habits to
Compulsion. Nature Neuroscience, 8(11) 1481-1489.

[23] Goode, E. (2014) Deviant Behaviour, Upper Saddle River: Prentice Hall.

[24] Heyman, G. M., (2009). Resolving the Contradictions of Addiction. Behavioural and Brain Sciences 19 (4): 561-610.

[25] Hayman M. (2005). The dopamine hypothesis of drug addiction: hypo dopaminergic state. International Review of Neurobiology, 62.101-

153.http://rstb.royalsocietypublishing.org/content/363/1507/31 13/F1.expansion.html.

[26] Idowu, F. (21 $1^{\text {st }}$ January 2014); Kano tops drug abuse chart Nigeria Vanguard Newspaper. P 33.

[27] Jiloha R. C. (2009) Social and Cultural Aspects of Drug Abuse in Adolescents Department of Psychiatry, MAMC \& GB Pant Hospital, New Delhi 110002.

[28] Johnston, L. D., O'Malley, P. M., Bachman, J. G., \& Schulenberg, J. E. (2011). Motivationing the future national results on adolescent drug use: overview of key findings Ann Arbor: Institute for Social Research, The University of Michigan.

[29] Levinthal, C. F. (2010). Drugs, Behaviour, and Modern Society. Allyn and Bacon, Boston.

[30] Lynch BS. and Bonnie RJ. Growing up tobacco free 2007: Preventing nicotine addiction in children and youths. Washington, DC: National Academy Press.

[31] Moses V. D., (2010). The Role of Dopamine in Human Addiction: From Reward to Motivated Attention. European Journal of Pharmacology, 526(1-3).

[32] Moses k. (2010) prevalence of drug abuse among undergraduate students of university of IlorinKausar press; Ibadan Nigeria.

[33] Nutt, D.; King, L. A.; Saulsbury, W.; Blakemore, C. (2010). "Development of a rational scale to assess the harm of drugs of potential misuse". The Lancet: 1047-1053.

[34] National Drug law Enforcement Agency (NDLEA, 2011) Report on incidence of drug abuse in Nigeria.

[35] National Institute on Drug Abuse, (NIODA, 2013) Drugs and their effect. Washington DC USA.

[36] National Survey on Drug Use and Health [NSDUH] 2013). U.S.A.

[37] National Institute on Alcohol Abuse and Alcoholism. (2005). Module 10F: Immigrants, refugees and alcohol. In NIAAA: Social work education for the prevention and treatment of alcohol use disorders (NIH publication). Washington, D. C.

[38] Parrot, A. (2006). Understanding Drugs and Behaviour. John Wiley \& Sons: England.

[39] Rockville, MD (2005) Center for Substance Abuse Treatment. "The Science of Addiction: Simplified," Substance Abuse in Brief. Substance Abuse and Mental Health Services Administration.

[40] Substance Abuse and Mental Health Services Administration,( 2013) National Survey on Drug Use and Health: Summary of National Findings, NSDUH Series H-48, HHS Publication No. (SMA) 14-4863. Rockville, MD. 
[41] Severson H. H. and Lichtenstein. Drug abuse Prevention Programmes for Adolescents: Rationale and Review. In: Krasnegor $\mathrm{N}$ and Cataldo $\mathrm{M}$ (Eds) Child Health and Behaviour, New York, Miley, 200.

[42] Synder HN, Sickmund M. Juvenile Offenders and Victims: 2010 National Report. Washington, DC: National Center for Juvenile Justice.

[43] Schuckit, M. A. (2010). Low level of response to alcohol as a predictor of future alcoholism. American Journal of Psychiatry 151, 184-189.

[44] Substance Abuse and Mental health Service Administration [SAMHSA's].

[45] Safe and Drug Free Schools Control Policy (SDFCP).

[46] Taole k. (2009) research methodology: understanding research $2^{\text {nd }}$ edition campus press. India.
[47] The 2014 Global Drug Survey (GDS2014).

[48] United Nations Office on drugs and crime. (2012). World Drug Report issue (E.12.XI.1). Newyork: United Nations publication.

[49] United nations educational scientific and cultural organization (unesco, 2007) Kano city Nigeria.

[50] Winters KC. (2009) Treating Adolescents with Substance Use Disorders: An Overview of Practice Issues and Treatment Outcome. Substance Abuse; 20 (4): 203-225.

[51] West, Robert. (2005). Theory of Addiction. Blackwell Publishing, Oxford.

[52] World health organization (WHO, 2011). Global survey on substance abuse. 